\title{
Induction of hairy roots and plant regeneration from the medicinal plant Pogostemon Cablin
}

\author{
Han-Jing Yan ${ }^{1 *}$, Meng-ling He${ }^{1}$, Wei-Jian Huang ${ }^{1}$, Dong-mei $\mathrm{Li}^{2}$ and Xiao-fang $\mathrm{Yu}^{3}$ \\ 'School of Traditional Chinese Medicine, Guangdong Pharmaceutical University, Guangzhou Higher Education Mega Center, Guangzhou Guangdong, 510006 China. \\ 2Shunde Polytechnic, Foshan 528300, China. \\ ${ }^{3}$ School of foreign languages, Guangdong Pharmaceutical University, Guangzhou Guangdong, 510006 China.
}

\begin{abstract}
An efficient transformation system for the medicinal and aromatic plant, Pogostemon cablin Benth was developed by using Agrobacterium rhizogenes ATCC15834 and C58C1. Hairy roots formed directly from the cut edges of leaf explants after infection for 2 days. The highest frequency of leaf explant transformation by A. rhizogenes ATCC15834 and C58C1 were $83.3 \%$ and $80.5 \%$ after pre culture about 2 days and infection by the bacterium containing $15 \mathrm{mg} \mathrm{l}^{-1}$ acetosyringone about $25 \mathrm{~min}$. The PCR amplification showed that rolB genes of Ri plasmid of $A$. rhizogenes were integrated and expressed into the genome of transformed hairy roots. The optimum medium for callus induction of hairy roots consisted of $2.0 \mathrm{mg} \mathrm{l}^{-1}$ $\mathrm{BA}$ and $0.1 \mathrm{mg} \mathrm{l}^{-1} \mathrm{NAA}$ while optimum medium for adventitious shoot regeneration from these cultures consisted of $0.1 \mathrm{mg} \mathrm{t}^{-1} \mathrm{BA}$ and $0.1 \mathrm{mg}$ $\mathrm{I}^{-1}$ NAA. Adventitious shoots could be rooted on $1 / 2 \mathrm{MS}$. PCR analysis confirmed that rol $B$ gene of TLDNA of Ri plasmid was integrated into the
\end{abstract}

genome of hairy roots-regenerated $P$. cablin plants. The results presented provide a possibility for breeding of a new cultivar of $P$. cablin.

Key words: Pogostemon cablin, Agrobacterium rhizogenes, Plant regeneration, C58C1, ATCC15834.

Address for Correspondence:

Dr. Han-Jing Yan, School of Traditional Chinese Medicine, Guangdong Pharmaceutical University, Guangzhou Higher Education Mega Center, Guangzhou Guangdong, 510006 China.

Phone no: 0086-20-39352176

E-mail: yanhanjing1211@163.com

DOI : 10.5530/pj.2016.1.11

\section{INTRODUCTION}

Pogostemon cablin, of the genus Pogostemon, is a perennial herbal plant native to the Philippines. It is a traditional chinese medicinal material commonly used in removing dampness, relieving summerheat, exterior syndrome, stopping vomiting and stimulating the appetite. Recent studies showed that $P$. cablin has an in vitro antivirus effect. ${ }^{1-3}$ In China, $P$. cablin is propagated by cutting propagation generally because it doesn't bloom in southern China. This mode of reproduction leads to weaker resistance of progeny and decline in yield and quality. ${ }^{4}$ It is very difficult to breed new cultivars using the traditional methods. Consequently, it is not only necessary to develop new technologies to create germplasm resources but also breed new cultivars. Many reports showed that genetic transformation of plants with Agrobactrium rhizogenes can be used as an efficient way of breeding new cultivars for improvement and creation of germplasm resources. ${ }^{5}$ So far, hairy roots which grow rapidly with stable and comparatively high content in secondary metabolites, induced by genetic transformation of $A$. rhizogenes, were successfully used for the production of essential oils from medicinal or aromatic plants, such

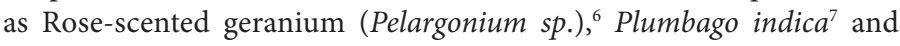
Psoralea drupacea (Fabaceae) ${ }^{8}$ and for improvement and creation of germ- plasm for Nierembergia scoparia, ${ }^{9}$ Kalanchoe blossfeldiana ${ }^{10}$ and Glycine max. The transgenic plants also produced from hairy roots are usually non-chimeric because the hairy roots originate from single cells and each hairy root consists of uniformly transformed cells. To date, there are only a few reports on breeding transgenic $P$. cablin plants with pest resistance by genetic transformation with A. tumefaciens. ${ }^{11-12}$ In the present study, we will describe the development of an efficient system for genetic transformation of the medicinal and aromatic plants $P$. cablin with $A$. rhizogenes and its plant regeneration from hairy roots.

\section{MATERIALS AND METHODS}

\section{Plant material}

P. cablin was cultivated in the medicinal botanical garden of Guangdong Pharmaceutical University. Leaves were sterilized, cut and placed at the medium of $\mathrm{MS}^{13}$ (Murashige and Skoog 1962) + $0.1 \mathrm{mg} \mathrm{l}^{-1} \mathrm{NAA}+0.2 \mathrm{mg}$ $\mathrm{l}^{-1} \mathrm{BA}$, then cultured at $25^{\circ} \mathrm{C}$ under a $14 \mathrm{~h}$ photoperiod.

\section{Bacterial Strains and Culture Conditions}

A. rhizogenes strains ATCC15834 and the disarmed A. tumefaciens strain C58C1 (which carries A. rhizogenes Ri plasmid pRiA4) ${ }^{14}$ were used to determine the transformation efficiency. The bacterial strain ATCC15834 and $\mathrm{C} 58 \mathrm{C} 1$ were shaken at $28^{\circ} \mathrm{C}$ in liquid YEB medium in the dark supplemented with $40 \mathrm{mg} \mathrm{l}^{-1}$ rifampcine, respectively. These strains were cultured in $25 \mathrm{~mL}$ of YEB on a gyratory shaker at $160 \mathrm{rpm}$ for 10 $\mathrm{h}$ at $28^{\circ} \mathrm{C}$ until the OD600 was approximately 1.0. The bacterial suspension was centrifuged at 5,000 rpm for $10 \mathrm{~min}$ and the pellet was resuspended in $50 \mathrm{~mL} \mathrm{1/2}$ MS liquid medium and used for co-cultivation of explants.

\section{Induction and culture of P. cablin hairy roots}

Young leaves (second and third leaves from the apex) excised from the seedlings which were micropropagated 25 days after last subculture were cut into $1.0-1.5 \mathrm{~cm}^{2}$ leaf explants and pre-cultured in the dark at $25^{\circ} \mathrm{C}$ on solid, growth regulator-free MS medium for $24 \mathrm{~h}, 48$ $\mathrm{h}$ and $72 \mathrm{~h}$. The leaf explants were then infected by dipping them into Agrobacterium suspension containing $10 \mathrm{mg} \mathrm{l}^{-1}, 15 \mathrm{mg} \mathrm{l}^{-1}$ and $20 \mathrm{mg}$ $\mathrm{l}^{-1}$ acetosyringone for $10 \mathrm{~min}, 15 \mathrm{~min}, 20 \mathrm{~min}, 25 \mathrm{~min}$, and $30 \mathrm{~min}$. Following infection, the agrobacterium suspension was blotted with sterilized filter paper to remove excess agrobacterium. After 1, 2 or 3 days of co-cultivation on solid, hormone free MS medium at $28^{\circ} \mathrm{C}$ 
in the dark, the leaf explants were transferred and placed on the MS medium containing $500 \mathrm{mg} \mathrm{l}^{-1}$ cefotaxime (filter-sterile before addition to the medium) and kept at $25^{\circ} \mathrm{C}$, under a $14 \mathrm{~h}$ photoperiod to induce hairy roots. All leaves were sub cultured every 7 days until there was no plaque's appearance. Control explants were given the same treatment but were dipped in sterile growth regulator-free MS medium. Each treatment consisted of 36 explants and the infection experiments were repeated twice.

\section{PCR analysis of hairy roots}

The isolation of genomic DNA from $100 \mathrm{mg}$ of sterile hairy roots and natural (non-transformed) roots was conducted using the established methods of Zhou et al. ${ }^{15}$ Polymerase chain reaction (PCR) identification of the rooting locus genes rol B was performed using DNAs from the hairy root as template and the non-transformed roots as control. The primers of rol B was P1: 50-GCT CTT GCAGTG CTA GAT TT-30 P2: 50-GAA GGT GCA AGC TAC CTC TC $-30 .{ }^{16}$ For amplification, the PCR parameters of rol B consisted of a pre-denaturation step of $5 \mathrm{~min}$ at $94^{\circ} \mathrm{C}$, denaturation of $30 \mathrm{~s}$ at $94^{\circ} \mathrm{C}$ and 35 cycles (each consisting of $30 \mathrm{~s}$ at $58^{\circ} \mathrm{C}$ and $1 \mathrm{~min}$ at $72^{\circ} \mathrm{C}$ ), followed by a final extension at $72^{\circ} \mathrm{C}$ for $10 \mathrm{~min}$. The amplified products were detected by ethidum bromide staining after $0.8 \%$ agarose gel electrophoresis.

The induced hairy roots were placed in different mediums for screening the best medium.

\section{Plant regeneration from hairy roots}

To induce callus, the positive transformed hairy root, maintained on 6,7$\mathrm{V}$ medium, was excised into $2-3 \mathrm{~cm}$-long segments and transferred to the callus induction media, in which MS medium was supplemented with BA (1.0, 2.0 or $\left.3.0 \mathrm{mg} \mathrm{l}^{-1}\right)$ and NAA $\left(0,0.1\right.$ or $\left.0.2 \mathrm{mg} \mathrm{l}^{-1}\right)$ in combination, $3 \%(\mathrm{w} / \mathrm{v})$ sucrose and $0.7 \%(\mathrm{w} / \mathrm{v})$ agar Each treatment consisted of 15 segments of hairy roots ( 3 segments per flask). The percentage of callus induction was calculated 30 days after inoculation. To induce adventitious shoot formation, the yellow-green calli with vigorous growth were selected and then transferred into the medium $\mathrm{MS}+0.1 \mathrm{mg} \mathrm{l}^{-1} \mathrm{BA}+0.1$ mg $\mathrm{l}^{-1}$ NAA. Each treatment consisted of 15 calli of hairy roots ( 3 calli per flask).The flasks were then kept at $25^{\circ} \mathrm{C}$ under a $14 \mathrm{~h}$ photoperiod. When adventitious shoots formed from the calli of hairy roots were $3-4 \mathrm{~cm}$ long with 3 leaves and were excised and transferred into $1 / 2 \mathrm{MS}$ medium at $25^{\circ} \mathrm{C}$ under a $14 \mathrm{~h}$ photoperiod for root induction. 36 shoots were each transferred into the rooting medium. Rooting percentage (the rooted shoots/ total shoots $\times 100 \%$ ) and the frequency of rooting (mean number per shoot) were recorded after 2 weeks. 30 regenerated plantlets were subjected to acclimation, transplanted to potting soil, then kept in a greenhouse.

\section{$P C R$ analysis of hairy root-regenerated plants}

The method of PCR analysis was the same as that of hairy roots, but using the hairy root-regenerated plant as template and the non-trans-
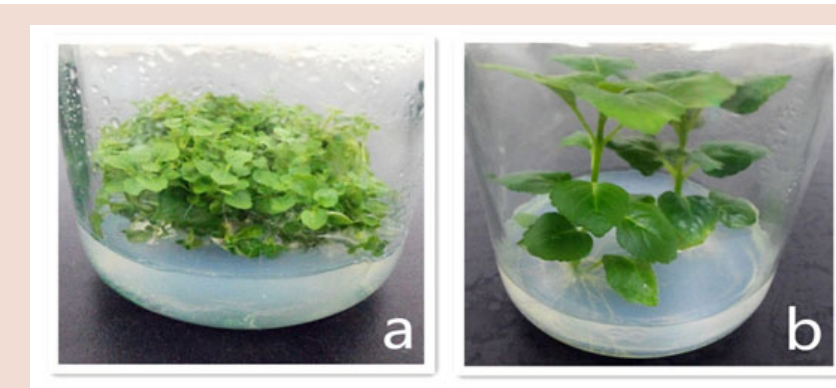

Figure 1: Induction of $P$. cablin aseptic seedling a. Calli and clump buds of $P$. cablin b: Seedlings of $P$. cablin. formed plant in flask as control. The amplified products were detected by ethidum bromide staining after $0.8 \%$ agarose gel electrophoresis.

\section{RESULTS}

\section{Induction and culture of $P$. cablin seedlings}

Leaves of $P$. cablin were cultured about 20 days, calli were induced and buds formed (Figure 1-a), buds elongated and shoots were transferred into 1/2 MS medium for rooting. Well-growth seedlings would be got after 30 days (Figure 1-b). The leaves of these seedlings were materials for hairy root-induction.

\section{Effect of pre-culture duration on transformation frequency}

Recent reports suggest that pre-culturing may influence the transformation frequency. ${ }^{17-18}$ Prior to infection with $A$. rhizogenes, stem sections were pre-cultured in MS medium for a varying period from 0 to 3 days, after which the standard procedure described in methods was used for the remaining part of the assay.

Transformation frequency differed depending on pre-culture time as shown in Table 1 . The results demonstrated that the transformation frequency could be improved after pre-culturing. The highest transformation frequency of two strains (> 80\%) were both observed after a 2 days pre-culture. The transformation frequency declined with an extended pre-culture time, with a 3-day pre-culture resulting in a decline of the transformation frequency. Thus, a 2-day pre-culture was used to test the effects of the following parameters on the transformation frequency.

Table 1: Effect of pre culture time on induction rate of $P$. cablin hairy roots

\begin{tabular}{ccccc}
\hline $\begin{array}{c}\text { Pre culture } \\
\text { time (d) }\end{array}$ & A. rhizogenes & $\begin{array}{c}\text { Number } \\
\text { of } \\
\text { explants }\end{array}$ & $\begin{array}{c}\text { Number of } \\
\text { explants } \\
\text { with roots }\end{array}$ & $\begin{array}{c}\text { Transformation } \\
\text { rate (\%) }\end{array}$ \\
\hline \multirow{2}{*}{$\mathbf{1}$} & ATCC15834 & 36 & 27 & 75.0 \\
& C58C1 & 36 & 24 & 66.7 \\
\multirow{2}{*}{$\mathbf{2}$} & ATCC15834 & 36 & 30 & 83.3 \\
& C58C1 & 36 & 29 & 80.5 \\
3 & ATCC15834 & 36 & 24 & 66.7 \\
& C58C1 & 36 & 21 & 58.3 \\
\hline
\end{tabular}

\section{Effect of acetosyringone (AS) concentration on induction rate of $P$. cablin hairy roots}

The concentration of AS had influence on induction rate of $P$. cablin hairy roots (Table 2). Induction rate of $A$. rhizogenes ATCC15834 and $\mathrm{C} 58 \mathrm{C} 1$ both reached the highest with $15 \mathrm{mg} \mathrm{l}^{-1} \mathrm{AS}$. A. rhizogenes couldn't recognize the host cells with lower concentration of AS, and the toxic effect of higher concentration of AS would block the combination of A. rhizogenes and the host cell.

Table 2: Effect of $A$. rhizogenes strain with their ability to induce hairy roots on various concentrations of acetosyringone (AS)

\begin{tabular}{ccccc}
\hline $\begin{array}{c}\text { AS } \\
\text { (mg/L) }\end{array}$ & A. rhizogenes & $\begin{array}{c}\text { Total } \\
\text { number } \\
\text { of explants }\end{array}$ & $\begin{array}{c}\text { Number of } \\
\text { explants with } \\
\text { roots }\end{array}$ & $\begin{array}{c}\text { Transformation } \\
\text { rate (\%) }\end{array}$ \\
\hline \multirow{2}{*}{$\mathbf{1 0}$} & ATCC15834 & 36 & 21 & 58.3 \\
& C58C1 & 36 & 9 & 25.0 \\
\multirow{2}{*}{$\mathbf{5}$} & ATCC15834 & 36 & 25 & 68.1 \\
& C58C1 & 36 & 18 & 50.0 \\
\multirow{2}{*}{$\mathbf{2 0}$} & ATCC15834 & 36 & 5 & 13.9 \\
& C58C1 & 36 & 16 & 44.4 \\
\hline
\end{tabular}


Table 3 : Effect of infection time on induction rate of $P$. cablin hairy roots

\begin{tabular}{ccccc}
$\begin{array}{c}\text { Infection } \\
\text { time (min) }\end{array}$ & A. rhizogenes & $\begin{array}{c}\text { Number } \\
\text { of } \\
\text { explants }\end{array}$ & $\begin{array}{c}\text { Number of } \\
\text { explants } \\
\text { with roots }\end{array}$ & $\begin{array}{c}\text { Transformation } \\
\text { rate (\%) }\end{array}$ \\
\hline \multirow{2}{*}{$\mathbf{1 0}$} & ATCC15834 & 36 & 25 & 68.1 \\
& C58C1 & 36 & 18 & 50.0 \\
\multirow{2}{*}{$\mathbf{5}$} & ATCC15834 & 36 & 21 & 58.3 \\
& C58C1 & 36 & 24 & 66.7 \\
\multirow{2}{*}{$\mathbf{2 0}$} & ATCC15834 & 36 & 26 & 72.2 \\
\multirow{2}{*}{$\mathbf{2 5}$} & C58C1 & 36 & 28 & 77.8 \\
& ATCC15834 & 36 & 29 & 80.5 \\
\multirow{3}{*}{$\mathbf{3 0}$} & C58C1 & 36 & 29 & 80.5 \\
& ATCC15834 & 36 & 24 & 66.7 \\
& C58C1 & 36 & 23 & 63.9 \\
\hline
\end{tabular}

Table 4 : Effect of co-culture time on induction rate of $P$. cablin hairy roots

\begin{tabular}{ccccc}
\hline $\begin{array}{c}\text { Co } \\
\text { culture } \\
\text { time (d) }\end{array}$ & A. rhizogenes & $\begin{array}{c}\text { Number } \\
\text { of } \\
\text { explants }\end{array}$ & $\begin{array}{c}\text { Number of } \\
\text { explants } \\
\text { with roots }\end{array}$ & $\begin{array}{c}\text { Transformation } \\
\text { rate (\%) }\end{array}$ \\
\hline \multirow{2}{*}{$\mathbf{1}$} & ATCC15834 & 36 & 15 & 41.7 \\
& C58C1 & 36 & 14 & 38.9 \\
$\mathbf{2}$ & ATCC15834 & 36 & 30 & 83.3 \\
& C58C1 & 36 & 29 & 80.5 \\
$\mathbf{3}$ & ATCC15834 & 36 & 20 & 55.6 \\
& C58C1 & 36 & 21 & 58.3 \\
\hline
\end{tabular}

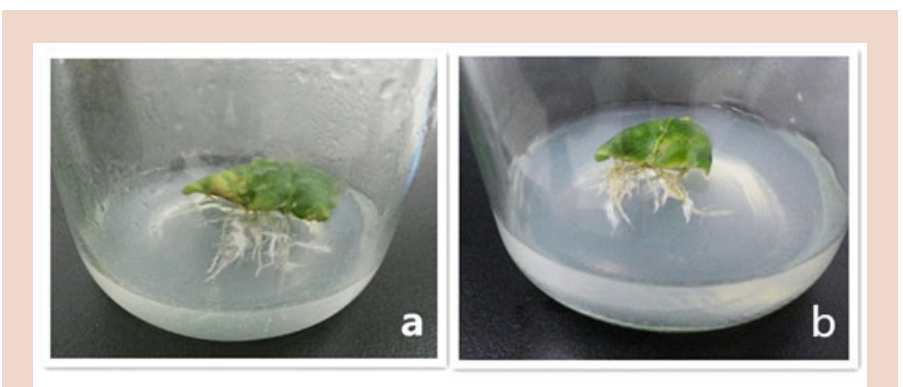

Figure 2: Hairy roots of $P$. cablin induced by Agrobacterium rhizogenes ATCC15834 and C58C1 a : Hairy roots of P. cablin induced by ATCC15834; $\mathrm{b}$ : Hairy roots of $P$. cablin induced by $\mathrm{C} 58 \mathrm{C} 1$.

\section{Effect of infection time on induction rate of P. cablin hairy roots}

Both $A$. rhizogenes strains reached the highest transformation rate after 25 min infection (Table 3).

Effects of co-culture time on induction rate of $P$. cablin hairy roots After infection, the explants were placed on the hormone free MS medium to allow T-DNA transfer from the plasmid into plant cells.

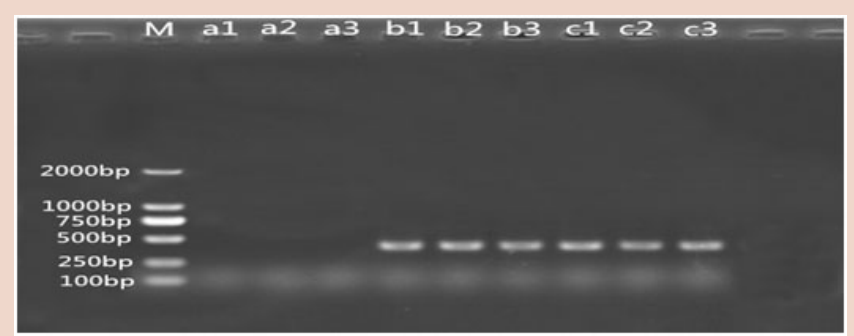

Figure 3: $P C R$ analysis of $P$. cablin hairy roots. $M$ : DL 2000 DNA marker a1, a2, a3: fragment amplified from $P$. cablin untransformation root; b1, b2, b3: fragment amplified from hairy roots of $P$. cablin induced by ATCC15834; $\mathrm{c} 1, \mathrm{c} 2, \mathrm{c} 3$ : fragment amplified from hairy roots of $P$. cablin induced by $\mathrm{C} 58 \mathrm{C} 1$.

Co-cultivation duration was tested in order to assess its impact on transformation frequency, the stem sections with one node were precultured for 2 days, infected with $A$. rhizogenes corresponding to OD600 around 1.0 and then placed on MS medium at $25^{\circ} \mathrm{C}$ for 1,2 or 3 days. After this, the explants were placed on MS medium containing $500 \mathrm{mg} \mathrm{l}^{-1}$ cefotaxime for hairy root production. As shown in Table 4, both two highest transformation frequency $(83.3 \%$ and $80.5 \%)$ were achieved with a 2-day co-cultivation. The transformation frequency was lower at both shorter and prolonged co-cultivation.

\section{Induction of hairy roots}

When leaf explants were inoculated with freshly grown A. rhizogenes suspensions in MS medium, hairy roots were induced directly from the cut edges of leaf explants (Figure 2). The first adventitious roots were visible 8 days after inoculation. With increasing incubation time, the percentages of rooted leaf explants also increased. The frequency of explants with adventitious root formation 25 days after inoculation with A. rhizogenes ATCC15834 and C58C1 were about $83.3 \%$ and $80.5 \%$ respectively. The hairy roots had characteristics of transformed roots such as high lateral branching and lack of gravitopism. As a control, adventitious roots excised from $P$. cablin sterile plants were cultured on solid, growth regulator-free MS medium, these roots without lateral roots were observed to grow very slowly and died after 18 days.

Hairy roots were placed on different mediums like MS, 1/2MS, 6-7V and B5, it was found that hairy roots grew slowly in these mediums, but slowly browned in 6-7V relatively.

\section{$P C R$ analysis of hairy roots}

Rol B is one gene of the TL-DNA (T-DNA left arm) of Ri plasmid in A. rhizogenes. In this study, by using DNAs from the hairy roots as template and the non-transformed roots as control, PCR products amplified with rol B primers, could be detected (Figure 3). It was demonstrated that rol B fragment (423bp) was amplified from hairy root cultures and the colony of $A$. rhizogenes but not from untransformed roots. The result indicated that the rol $\mathrm{B}$ gene from the Ri plasmid of $A$. rhizogenes

Table 5 : Results of callus induction of hairy root induced by Agrobacterium rhizogenes ATCC15834

\begin{tabular}{|c|c|c|c|c|c|c|}
\hline No. & $\begin{array}{l}\text { 6-BA/ } \\
\text { (mg/L) }\end{array}$ & $\begin{array}{l}\text { NAA/ } \\
\text { (mg/L) }\end{array}$ & $\begin{array}{c}\text { Number of hairy } \\
\text { roots }\end{array}$ & $\begin{array}{l}\text { Number } \\
\text { of calli }\end{array}$ & $\begin{array}{c}\text { Induction rate of } \\
\text { calli(\%) }\end{array}$ & Growth state \\
\hline 1 & 0.0 & 0 & 15 & 0 & 0.00 & No calli \\
\hline 2 & 1.0 & 0 & 15 & 10 & 66.67 & Light-green, loose \\
\hline 3 & 2.0 & 0 & 15 & 12 & 80.00 & Light-green, compact \\
\hline 4 & 3.0 & 0 & 15 & 12 & 80.00 & Light-yellow, loose \\
\hline 5 & 2.0 & 0.1 & 15 & 15 & 100.00 & Light-yellow, loose \\
\hline 6 & 2.0 & 0.2 & 15 & 14 & 93.33 & Light-green, compact \\
\hline
\end{tabular}


Table 6 : Results of callus induction of hairy root induced by Agrobacterium rhizogenes C58C1

\begin{tabular}{ccccccc} 
No & $\begin{array}{c}\mathbf{6}-\mathbf{B A} / \\
(\mathbf{m g} / \mathbf{L})\end{array}$ & $\begin{array}{c}\text { NAA/ } \\
(\mathbf{m g} / \mathbf{L})\end{array}$ & $\begin{array}{c}\text { Number of hairy } \\
\text { roots }\end{array}$ & $\begin{array}{c}\text { Number } \\
\text { of calli }\end{array}$ & $\begin{array}{c}\text { Induction rate of } \\
\text { calli(\%) }\end{array}$ & $\begin{array}{c}\text { No calli } \\
\text { Growth state }\end{array}$ \\
\hline $\mathbf{1}$ & 0 & 0 & 15 & 0 & 0.00 & Light-green,compact \\
$\mathbf{2}$ & 1.0 & 0 & 15 & 10 & 66.67 & Light-green,loose \\
$\mathbf{3}$ & 2.0 & 0 & 15 & 13 & 86.67 & Light-green,compact \\
$\mathbf{4}$ & 3.0 & 0 & 15 & 12 & 80.00 & Light-yellow,loose \\
$\mathbf{5}$ & 2.0 & 0.1 & 15 & 15 & 100.00 & Light-yellow,compact \\
$\mathbf{6}$ & 2.0 & 0.2 & 15 & 13 & 86.67 & \\
\hline
\end{tabular}
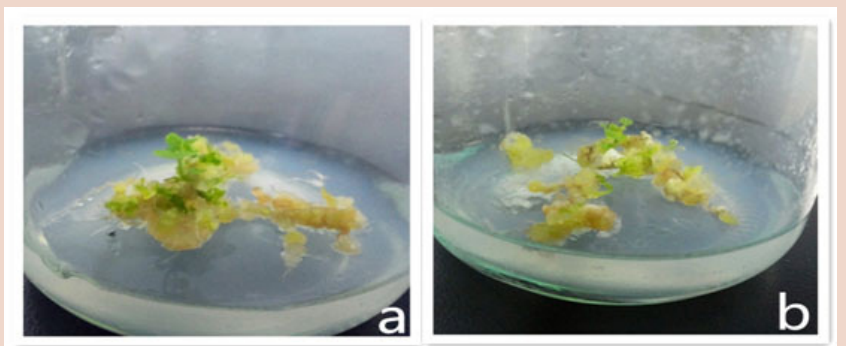

Figure 4: Calli from hairy roots of $P$. cablin a : Calli from hairy root induced by Agrobacterium rhizogenes $\mathrm{C} 58 \mathrm{C} 1: \mathrm{b}:$ Calli from hairy root induced by Agrobacterium rhizogenes ATCC15834.

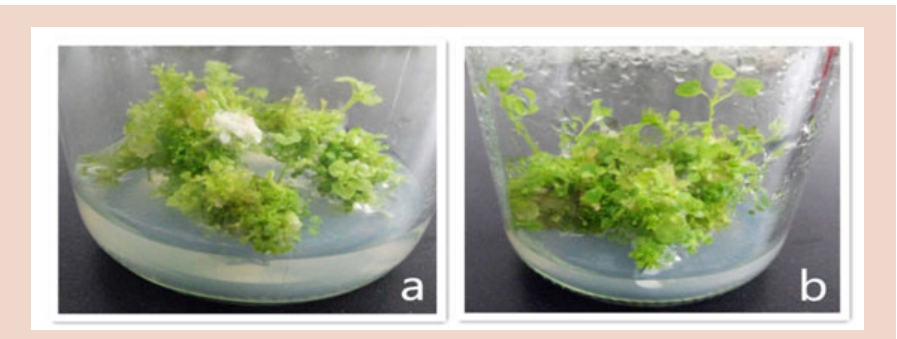

Figure 5: Buds induction from callus of $P$. cablin hairy root a : Buds induction from Callus of hairy root induced by Agrobacterium rhizogenes $\mathrm{C}_{58} \mathrm{C} 1$; b : Buds induction from Callus of hairy root induced by Agrobacterium rhizogenes ATCC15834.

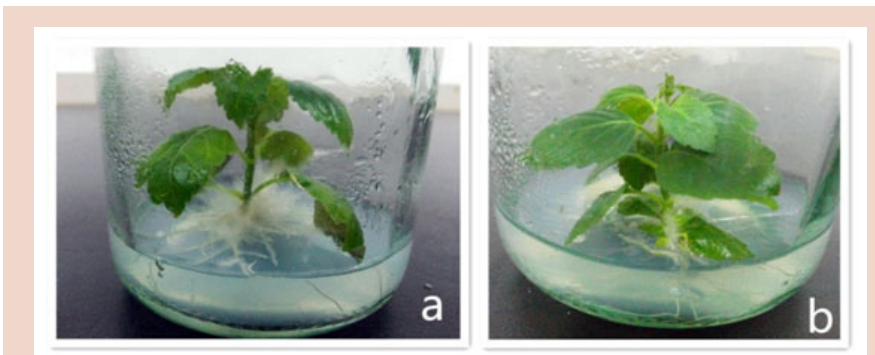

Figure 6: Regeneration plant of hairy root induced by $P$. cablin a Regeneration plant of hairy root induced by Agrobacterium rhizogenes $\mathrm{C} 58 \mathrm{C} 1$; b : Regeneration plant of hairy root induced by Agrobacterium rhizogenes ATCC15834.

ATCC15834 and C58C1 was integrated and expressed into the genome of $P$. cablin hairy roots.

\section{Plant regeneration from hairy roots}

When $2-3 \mathrm{~cm}$ root segments excised from the transformed hairy root were transferred into the callus induction medium for 7 days, the segments of hairy roots began to swollen and formed small light-green

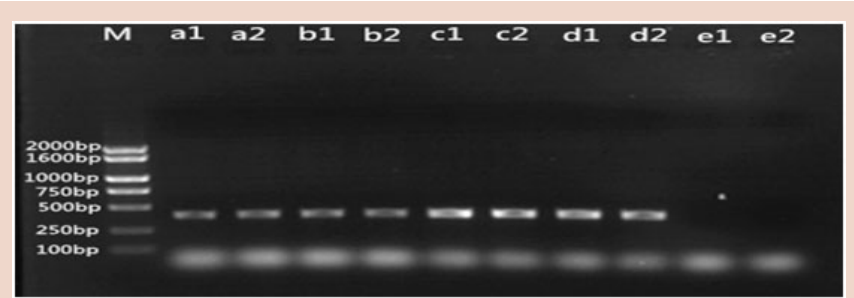

Figure 7: $P C R$ analysis of regeneration plant of hairy root induced by P. cablin M: 100 bp DNA marker; a1, a2: fragment amplified from regeneration plant 1 of hairy root induced by A. rhizogenes ATCC15834; b1, b2: fragment amplified from regeneration plant 2 of hairy root induced by $A$. rhizogenes ATCC15834; $\mathrm{C1}$, C2: fragment amplified from regeneration plant 1 of hairy root induced by $A$. rhizogenes $\mathrm{C} 58 \mathrm{C} 1$; $\mathrm{d} 1$, d2: fragment amplified from regeneration plant 2 of hairy root induced by $A$. rhizogenes $\mathrm{C} 58 \mathrm{C} 1$; e1, e2: fragment amplified from $P$. cablin aseptic seedling.

calli from the cut ends. After 30 days, the formation rates of calli were counted (Table 5 and 6).

The highest rate of calli induction was obtained at MS+2.0 $\mathrm{mg} \mathrm{l}^{-1} \mathrm{BA}+0.1$ $\mathrm{mg} \mathrm{l}^{-1} \mathrm{NAA}$, where the hairy roots could form light-yellow and loose calli. Some calli began to differentiate adventitious buds (Figure 4).

When transferred into shoot inducing medium $\mathrm{MS}+0.1 \mathrm{mg} \mathrm{l}^{-1} \mathrm{BA}+0.1$ $\mathrm{mg} \mathrm{l}^{-1}$ NAA for 35 days, they began to form adventitious buds at a frequency of $100 \%$, a lot of buds were generated and grew well (Figure 5).

When adventitious shoots were $3-4 \mathrm{~cm}$ height with 3 leaves, strong shoots were chosen and transferred to $1 / 2 \mathrm{MS}$ medium for rooting. Cultures grown in complete darkness had thickened roots. The regenerated shoots were vigorous in appearance with dark-green and wide leave (Figure 6). Wrinkling of leaves in hairy root-transformants is common and has been reported in several species as a symptom developed after insertion of the Ri T DNA of $A$. rhizogenes. ${ }^{19-20} \mathrm{Mei}^{21}$ reported wrinkle-free normal leaves in transformed plants of Alhagi pseudoalhagi.

And there were many adventitious roots with high lateral branching and lack of geotropism formed on the contact surface of the regenerated plant and the medium.

\section{$P C R$ analysis of regeneration plant}

PCR products amplified with rol B primers could be detected (Figure 7). It was demonstrated that rol B fragment (423bp) was amplified from the regenerated plant of hairy root but not from untransformed plant. The result indicated that the rol $\mathrm{B}$ gene from the Ri plasmid of $A$. rhizogenes ATCC15834 and C58C1 was integrated and expressed into the genome of regenerated plant of $P$. cablin hairy roots. The rooted plantlets were transferred to greenhouse conditions where they showed about 95\% survival.

\section{DISCUSSION}

A. rhizogenes causes hairy root disease in plants. The neoplastic (cancerous) roots produced by $A$. rhizogenes infection are characterized by high growth rate, genetic stability and growth in hormone free media. 
These genetically transformed root cultures can produce levels of secondary metabolites comparable to that of intact plants. Hairy root cultures offer promise for high production and productivity of valuable secondary metabolites (used as pharmaceuticals, pigments and flavors) in many plants. ${ }^{22}$ But the introduction of hairy roots still can be affected by many factors.

AS is an amino acid derivative and a phenolic compound, which must be constant for biological activity and maintenance of vir gene expression in Muskmelon explants. ${ }^{23}$ Many other reports also pointed out that the vir genes are inducible in response to the monocyclic phenolic compound like AS. ${ }^{24}$ The results obtained from higher $(20 \mathrm{mg} \mathrm{l-1)}$ concentration of AS indicated an inhibitory action rather than stimulatory.

A. rhizogenes C58C1, a disarmed Agrobacterium tumefaciens, is widely used for the production of important pharmaceutical or aromatic chemicals from many medicinal plants, such as Anisodus acutangulus, ${ }^{25}$ Linum Album ${ }^{26}$ and Camptotheca acuminate. ${ }^{27}$ Wang reported that camptothecin and 10-Hydroxy-camptothecin detected in the hairy roots inducted from $\mathrm{C} 58 \mathrm{C} 1$ was the highest and $\mathrm{C} 58 \mathrm{C} 1$ was the best one in the study of effects of different strains (including A4, 15834, R1601 and $\mathrm{C} 58 \mathrm{C} 1$ ) on induction of hairy roots from Camptotheca acuminate. ${ }^{27}$ In our study, A. rhizogenes $\mathrm{C} 58 \mathrm{C} 1$ could induce the hairy roots of P.cabin.

Pre-culture time had some effect on the transformation rate. The cut on the leave would go brown after infection, which could cause low induction rate. But after a period of pre-culture, the cell of cut in explants began to divide and get into competence which could increase the transformation rate. In our study, 2 days was the best processing time, but Lu reported 3 days was the best pre culture time for transformation in hairy roots induction of Hyoscyamus niger, ${ }^{28}$ and the transformation rate would decrease sharply with the pre culture time over 3 days.

Although hairy roots were induced successfully by ATCC15834 and C58C1, those hairy roots didn't grow fast. PCR analysis indicated that the hairy root gene had been transferred into, so it was speculated that TR-DNA which was responsible for the hormone synthesis was not transformed into hairy roots. It was suspectd that A. rhizogenes may have some effects on the second metabolites of the regenerated plants of hairy roots, so the chemical constituents of the regenerated plants would be studied further.

\section{ACKNOWLEDGEMENT}

This study was financially supported by the Science and Technology Plan Program of Guangdong Province, P. R. China (2015A030302084).

\section{ABBREVIATION USED}

BA: Benzyladenine, MS: Murashige and Skoog, NAA: Naphthaleneacetic acid, Ri: Root inducing, rol B: Rooting locus B, rol C: Rooting locus C, YEB: Yeast Extract Broth, AS: Acetosyringone, PCR: Polymerase Chain Reaction.

\section{REFERENCES}

1. Kiyohara HC, Ichino Y, Kawamura T, Nagai N, Sato H, Yamada. Patchouli alcohol: in vitro direct anti-influenza virus sesquiterpene in Pogostemon cablin Benth. J Nat Med. 2012; 66(1): 55-61.

2. Peng SZ, Li G, Su Z, Su ZR, Zhan FX, Lai XP. Effect of different extract parts of Pogostemon cablin( Blanco) Benth on in vivo anti-influenza virus. Lishizhen Med Mater Med Res. 2011; 22(1): 2578-9.

3. Wang YT, Yang ZF, Zhao SS, Qin S, Guan WD, Huang QD. et al. Screening of anti-H1N1 active constituents from Radix Isatidis. J Guangzhou Univ Tradit Chin Med. 2011; 28(4): 419-22.

4. $\mathrm{Lin} \mathrm{XH}, \mathrm{He} \mathrm{H}$. Problem and investigation status on germplasm resources in patch- ouli (Pogostemon cablin (Blanco) Benth). Res Pract Chin Med. 2005; 19(4): 60-2.

5. Zia M, Mirza B, Malik SA, Chaudhary MF. Expression of rol genes in transgenic soybean (Glycine max L.) leads to changes in plant phenotype leaf morphology, and flowering time. Plant Cell Tiss Organ Cult. 2010; 103(2): 227-36.

6. Saxena G, Banerjee S, Laiq-ur-Rahman Verma PC, Mallavarapu GR, Umar S. Rose-scentedgeranium (Pelargonium sp.) generated by Agrobacterium rhizogenes mediated Ri-insertion for improved essential oil quality. Plant Cell Tiss Organ Cult. 2007; 90(2): 215-23.

7. Gangopadhyay M, Chakraborty D, Bhattacharyya S, Bhattacharya S. Regeneration of transformed plants from hairy roots of Plumbago indica. Plant Cell Tiss Organ Cult. 2010; 102(1): 109-14

8. Lystvan K, Belokurova V, Sheludko Y, Ingham JL, Prykhodko V, Kishchenko O, et al. Production of bakuchiol by in vitro systems of Psoralea drupacea Bge. Plant Cell Tiss Organ Cult. 2010, 101(1): 99-103.

9. Godo T, Tsujii O, Ishikawa K, Mii M. Fertile transgenic plants of Nierembergia scoparia sendmer obtained by a mikimopine type strain of Agrobacterium rhizogenes. Scientia Horticultura. 1997; 68(1): 101-11.

10. Christensen B, Sriskandarajak S, Serek M, Muller R. Trans- formation of Kalanchoe blossfeldiana with rol genes is useful in molecular breeding towards compact growth. Plant Cell Rep. 2008; 27(9): 1485-95.

11. Zhang JM, Sun XP, Zheng XQ. Construction of cecropin $B$ and $D$ double gene expression vector and transformation of patchouli (Pogostemon cablin Benth.) Chin J Trop Crop. 1997; 18(1): 52-7.

12. Sugimura $Y$, Kadotani N, Ueda Y, Shima K, Kitajima S, Furusawa T, et al. Transgenic patchouli plants produced by Agrobacterium-mediated transformation. Plant Cell Tiss Organ Cult. 2005; 82(3): 251-7.

13. Murashige T, Skoog F. A revised medium for rapid growth and bioassays with tobacco tissue culture. Physiol Plant. 1962; 15(3): 473-97.

14. Mozo T, Hooykaas PJJ. Electroporation of megaplasmids into Agrobacterium. Plant Mol Biol. 1991; 16(5): 971.

15. Zhou X, Cao GC, Lin R, Sun Y, LiW. A rapid and efficient DNA extraction method of genus Fagopyrum for RAPD analysis. -In: Javornik, B., Bohanec, B., Kreft, I. (ed.): Proceedings of Impact of Plant Biotechnology on Agriculture. Biotechnical Faculty, Ljubljana; 1994. 171-5.

16. Furner IJ, Huffman GA, Amasino RM, Garfinkel DJ, Gordon MP, Nester EW. An Agrobacterium transformation in the evolution of the genus Nicotiana. Nature 1986; 319(Issue Missing?): 422-7.

17. Barik DP, Mohapatra U, Chand PK. Transgenic grasspea (Lathyrus sativus L.): factors influencing Agrobacterium-mediated transformation and regeneration. Plant Cell Reports 2005; 24(9): 523-31.

18. Chen L, Zhang B, Xu Z. Salt tolerance conferred by over expression of Arabidopsis vacuolar $\left.\mathrm{Na}^{+}\right) / \mathrm{H}^{(+)}$antiporter gene AtNHX1 in common buckwheat (Fagopyrum esculentum). Transgenic Research 2008; 17(1): 121-32.

19. Sukanya Majumdar, Saraswati Garai, Sumita Jha. Genetic transformation of Bacopa monnieri by wild type strains of Agrobacterium rhizogenes stimulates production of bacopa saponins in transformed calli and plants. Plant Cell Reports 2011; 30(5): 941-54

20. Chaudhuri KN, Ghosh B, Tepfer D, Jha S. Spontaneous plant regeneration in transformed roots and calli from Tylophora indica: changes in morphological phenotype and tylophorine accumulation associated with transformation by Agrobacterium rhizogenes. Plant Cell Rep. 2006; 25(10): 1059-66.

21. Mei Wangyu, Jiangbo Wang, Da Luo, Jingfen Jia. Regeneration of plants from callus tissues of hairy roots induced by Agrobacterium rhizogenes on Alhagi pseudoalhagi. Cell Research 2001; 11(4): 279-84.

22. Srivastava S, Srivastava AK. Hairy root culture for mass-production of high-value secondary metabolites. Crit Rev Biotechnol. 2007; 27(1): 29-43.

23. Mohiuddin KM, Abdullah C, Harikrishna K, Chowdhury K, Napis S. Enhanced virulence gene activity of Agrobacterium in Muskmelon (Cucumis melon L.)cv. Birdie. Not. Sci. Biol. 2011; 3(2): 71-9.

24. Ridgway HJ, Kandula K, Stewart A. Optimizing production of carrot hairy roots. N. Z. Plant Prot. 2004; 57(8): 77-80.

25. Li Li, Jing Wang, Wei Wang, Yang Lu, Yuliang Wang, Genyu Zhou, et al. Optimization of induction and culture conditions and tropane alkaloid production in hairy roots of Anisodus acutangulus. Biotechnology and Bioprocess Engineering 2008; 13(5): 606-12.

26. Ahmadian Chashmi M, Sharifi M, Yousefzadi M, Behmanesh J, Palazon. The production of cytotoxic lignans by hairy root cultures of Linum Album. World Academy of Science Engineering and Technology 2011; 80(8): 401-2.

27. Wang Wei, Lu Yang, Li Li, Wang Jing, Kai Guo-yin. Induction of Hairy Roots from Camptotheca acuminatac and the Content of Camptothecin [J]. Acta Bot. Boreal.-Occident. Sin. 2008; 28(12): 2416-22.

28. Lu Bei-bei, Zhang Lei, Kai Guo-yin, Zhang Han-ming, Ding Ru-xian, Chen Wan-sheng. Establishment of hairy root culture of Hyoscyamus niger. Chinese Traditional and Herbal Drugs 2005; 36(12): 1864-8. 
PICTORIAL ABSTRACT

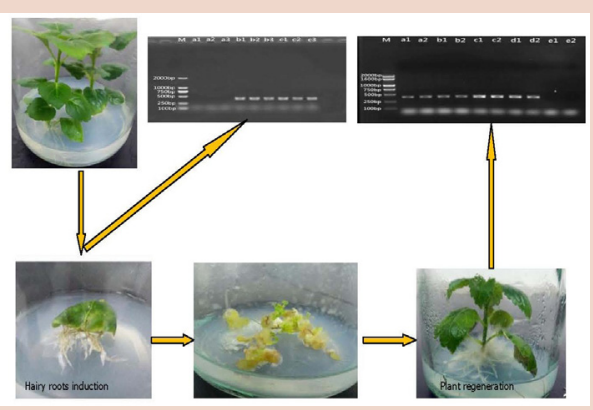

\section{SUMMARY}

- Hairy roots formed from the cut edges of leaf explants by using Agrobacterium rhizogenes ATCC15834 and $\mathrm{C} 58 \mathrm{C} 1$, but the hairy roots grew slowly.

- Plants could be regenerated from the hairy roots induced by Agrobacterium rhizogenes ATCC15834 and C58C1.

- The hairy roots and plants regenerated both contained rol B fragment of Agrobacterium rhizogenes.

\section{ABOUT AUTHOR}

Dr. Han-Jing Yan: An associate professor of the College of Traditional Chinese Medicine in Guangdong Pharmaceutical University, graduated from the College of Life Science, Sun Yat-sen University in 2007. She has been dedicating to the studies on physiology and biochemistry of the medicinal plants from southern China. And she is still working on the conservation of medicinal plant resources, quality evaluation, genetic diversity analysis and medicinal plant breeding by biological technologies. 